\title{
Challenges facing nursing education in Australia: Two solutions
}

\author{
Margaret Maura McAllister \\ School of Health and Sport Sciences, University of the Sunshine Coast, Australia \\ Correspondence: Margaret Maura McAllister. Address: Sippy Downs Drive, Maroochydore, DC4558. \\ Telephone: 75-456-5032. Email: mmcallis@usc.edu.au \\ Received: October 2, 2011 \\ DOI : $10.5430 /$ jnep.v2n1p20
}

\section{Abstract}

Background: Australia, like many other countries is facing a shortage of qualified nurse educators and this has potential to impact enormously on the quality of nurses working in health services.

Methods: This paper discusses the findings of action research recently completed within a Queensland University, involving a range of nurse educators.

Results: The paper explores some of the challenges to role satisfaction and suggests two strategies to build capacity, connection, satisfaction and productivity in Australian nurse educators that may be relevant for international colleagues.

Conclusions: The first solution is to establish a self-sustaining, solution-focused Community of Practice for nurse educators. The second solution is to disseminate an effective, easy to remember teaching framework that draws upon principles of Transformative learning, a pedagogy that is relevant for nurses, because they will need to work with vulnerable populations, and graduates will need to be equipped with skills, compassion and be committed to social action.

\section{Key words}

Action research, Community of practice, Curriculum development, Nurse education, Pedagogy, Threshold concepts, Transformative learning

\section{Introduction}

A serious consequence of the global, and apparently unabating, shortage of nurses is that there is now a recognised world-wide shortage of nurse educators ${ }^{[1,2]}$. In Australia nurse education is undertaken by full time and sessional nursing academics employed in the Higher Education (HE) sector, nurse teachers employed in the Vocational Education and Training (VET) sector, clinical or nurse educators employed in health services (Health), and clinical facilitators employed by any or all sectors.

The causes of this nurse educator shortage, according to US based studies ${ }^{[1,3]}$, and confirmed by an Australian study ${ }^{[4]}$, include: ageing faculty, heavy workload, low wages, lack of a robust nurse education pipeline, dissatisfaction with a teaching career because of high workloads and institutional pressures to revise curricula and develop educational approaches which better match the realities of clinical practice. Importantly, the US nursing researchers Aiken and 
Cheung $^{[5]}$ have argued that "if the lack of capacity in nurse education could be resolved, there would be no nursing shortage".

Related to the nursing educator shortage is the increasing reliance on sessional educators, who are employed on a part-time or casual basis ${ }^{[6]}$. Within Australia, sessional educators' input offers universities another avenue to assure clinical relevance in nursing programs, but there is also growing awareness of threats to quality and effectiveness in learning and teaching. There are many reasons for this concern. Sessional educators are very often selected for their clinical expertise, yet they usually lack educational training, and thus are at risk of teaching as they have been taught and /or unconsciously conveying out of date ideas about best teaching practice ${ }^{[7,8]}$. Despite a common rhetoric valuing transactional teaching practice, nursing educators have been observed to be continuing with a transmissional style, which leads to a concern for content coverage, curriculum overload, and a burden on students to absorb it all ${ }^{[9]}$. There is confusion and uncertainty about relevant pedagogies to drive teaching approaches ${ }^{[10]}$. There is also a tendency to deemphasize development of affective attributes such as empathy, compassion, and a social conscience ${ }^{[11,12]}$.

Several opportunities for systematic change are therefore needed. Two in particular are the focus for development at the University of the Sunshine Coast: 1) establishment of Communities of Practice to facilitate the sharing of educational expertise within nurse educators and 2) diffusion and dissemination of a simple, yet effective, educational framework that will assist diverse educators to re-establish balance within the nursing curriculum where technical as well as affective skills are developed. These two innovations will be discussed.

\section{Communities of practice amongst nurse educators}

In 2010, a qualitative study of diverse Australian nurse educators revealed that the pace of change in nursing is affecting the role ${ }^{[4]}$. Whilst educators continue to find their role rewarding, they are concerned about feeling isolated, and lacking time and mentorship to engage in dialogue about education. The likely consequence of this situation is that innovative teaching strategies and educational solutions to clinical and cultural problems will not be effectively shared and evidence-based teaching practice within nursing in Australia will stagnate.

There is an emerging and important need to reorient the nurse educator role so that educators can work smarter, more collaboratively, and apply research skills to resolve educational as well as clinical problems. The study ${ }^{[4]}$ confirmed the findings of research conducted elsewhere ${ }^{[13]}$ which indicates that many nurse educators practice in isolation and do not have networks or mentors to help them develop their teaching expertise or scholarship. Other research indicates that where innovations are occurring, resources are not effectively evaluated or shared, and the evidence base for nurse educators is not keeping pace with the challenges students and graduates face ${ }^{[14,15]}$. There is disconnection from each other, lack of succession planning and limited opportunities for educators to become familiar with new teaching technologies, evaluation and research concepts.

The National League for Nursing (NLN) in the United States provides a model that Australian nursing should consider. When it was founded in 1893 it established a community of practice amongst advocates for nursing education. It has since grown to be the main North American organization for nurse educators and provides a number of resources that help to sustain the profession and to build capacity: a research journal; certification for educators; accreditation for providers; annual conferences; research funding and awards for teaching and research excellence. It is hailed as "The voice for nursing education in the US” (http://www.nln.org/index.cfm).

In Australia, The Australian Nurse Teachers Society (ANTS) is the nearest equivalent. ANTS was established in 1972 and aims to be the independent professional body for nurse education. It has, however, tended to have more influence in only one Australian State (New South Wales) although it is currently seeking to strengthen its position nationally. But its membership is relatively small; it lacks finances and scale to provide similar resources to the NLN. 
As Palmer ${ }^{[16]}$ stated,

The growth of any craft depends on shared practice and honest dialogue among the people who do it. We grow by trial and error, to be sure - but our willingness to try, and fail, as individuals are severely limited when we are not supported by a community that encourages such risks.

Australian nurse educators would benefit from incentives to join a professional community, such as ANTS, in order to connect dispersed and diverse nurse educators. Wenger's ${ }^{[17]}$ concept of building shared purpose through a Community of Practice (CoP), provides a relevant theory to improve nurse educator communication and exchange. CoPs provide a context for sustained professional conversations around identified knowledge domains and practice issues ${ }^{[18]}$. For nursing education, a CoP has potential to change the culture from its present state of fragmentation, and to foster connection between isolated educators. People who feel ownership or a sense of belonging in their community may develop a strong sense of cultural identity and this may help to revitalise and unify the profession as one that appreciates its own unique knowledge and research base and works to extend it.

The vision is that educators would have: a shared repertoire of resources; a shared understanding and ability to examine recurring problems facing the community; positive experiences to build confidence and good will and shared stories for the enrichment of the expanding community and tools to work efficiently and effectively. There are risks to be aware of in establishing and then sustaining interaction amongst educators. For example, mentors need to be recruited and given incentives to support novices and show them the benefits of discussing the craft and value of building an evidence base in nursing education and technology, such a well-designed website that provides learning objects that can be shared, rated and extended may be a time-saver, but it also needs to be augmented with face to face connectivity so that people feel as though they are part of a real community. A Community of Practice could develop a shared knowledge base and new practices, and ultimately cross-sector exchange, enrichment and influence.

The strategy proposed is to seek funding to run focus groups and workshops. ANTS have agreed to host the focus groups at the national nurse educator conference. In these groups the range of needs participants have, will be explored in order to ensure content relevance for future workshops. Workshops will be conducted in each State of Australia. Groups of educators (particularly sessional) from the sectors (HE, VET and Health) will be facilitated to focus on generating and sharing educational solutions to three problems for nursing education in Australia: the first-year experience, clinical placement and graduate integration. In addition, issues previously identified as relevant will be explored. In order to develop a sense of belonging, shared purpose and grow the evidence base for nursing education, we intend to build a sense of community by holding workshops and facilitating networks in the virtual environment. Individuals and teams will be invited to enter into an agreement to post their emerging or completed work on the virtual environment and the project manager will agree to engage with them regularly to help them to meet their objectives and to update the site with inspiring material and resources. At various points during the work phase, members will be invited to reflect upon the process and to share their experiences. This will enable the team to correct difficulties and ensure aims are being achieved and members' needs are met. The final stage for members will be when outputs, achievements, activities and challenges are shared at the next ANTS national conference. This approach to dissemination will build members' confidence in scholarly activities. It also helps distribute new information for the benefit of students of nursing.

A second strategy identified as one solution to the problem of educators lacking confidence with education scholarship is to disseminate a simple teaching framework.

\section{STAR: A transformational learning framework}

In response to identified concerns about educators working in health disciplines lacking confidence and pedagogy, and resorting to teaching styles that were not interactive or engaging, a teaching framework was developed by the author that 
aimed to assist novice educators to teach more interactively, raise students' social conscience, and offer an explicit pedagogy and theory (Transformative Learning) to drive their practice.

Transformative Learning (TL), as defined in 2000 by Jack Mezirow ${ }^{[19]}$, is the process by which learners call into question taken-for-granted ideas, frames of reference, or habits of mind. TL has a focus on preparing students for a complex, changing world where entrenched problems require new approaches. Students are challenged to question assumptions, beliefs, feelings, and perspectives. They may need to learn to let go of accepted truths, develop new habits of mind, and take committed actions to be part of productive social change. The value of transformative learning for nursing students lies in its ability to awaken them to issues of injustice that lead to and sustain health inequities, and to promote in them critical thinking and questioning of previously-held assumptions, beliefs, values and perspectives, so that they may be part of systemic change.

Termed STAR, the framework acronym stands for Sensitise. Take Action and Promote Reflection and is discussed at length elsewhere ${ }^{[20]}$. It encapsulates transformative learning principles, and places an emphasis on the need for educators to raise students' awareness of health inequities and to equip learners with the technical and communicative skills to produce positive change. The framework aims to be a simple, easily-memorized framework that can assist educators to apply the principles of transformative learning (see Figure 1).

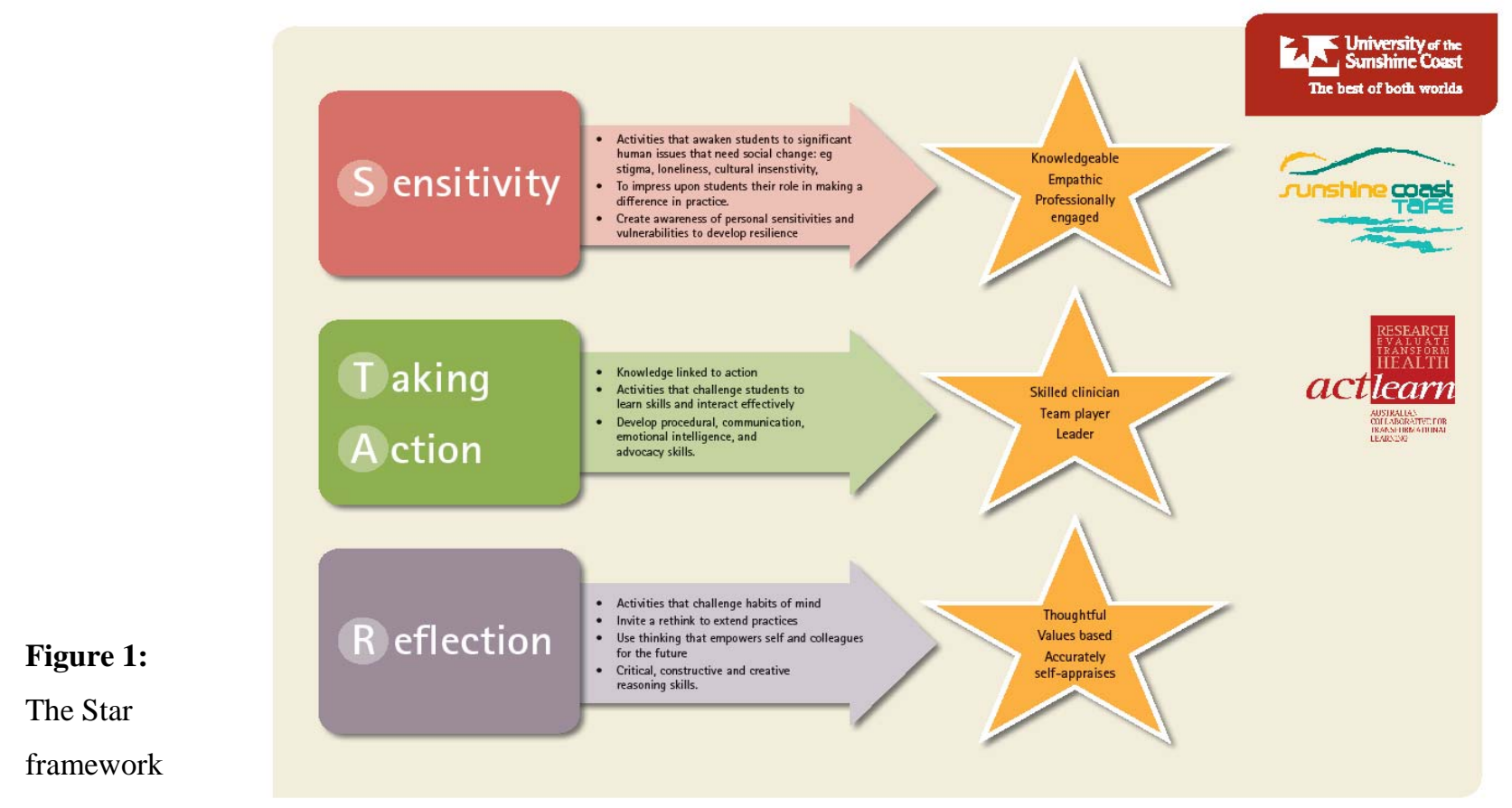

Underpinning the framework are the following assumptions that apply transformative learning theory:

1. Educators need to spend time sensitising students for the intended learning, and there is value in assessing students level of sensitivity to an issue, because students may have become desensitised, hold stigmatizing attitudes and feelings, or be ignorant about its significance. This will build affective skills such as compassion and empathy. There is value in reflecting upon issues, preparing for them, and developing an awareness of their complexity before going out into the clinical world where the issues will be confronted ${ }^{[21]}$. 
2. Rather than design curricula with an additive approach (what more needs to be added in?), educators can design curricula by identifying issues critical to that profession's practice ${ }^{[9]}$. These topics become threshold concepts for students - they are on the threshold for students, because once fully learned and appreciated, the student will never again look at the issue the same way. They will have crossed the threshold into a new way of seeing, and working as a health care professional ${ }^{[22]}$.

3. Educators need to include in their teaching processes opportunity for students to put knowledge into use, by taking action. Knowledge that is not linked to action is empty theorising. Actions that are not linked to theory are dangerous routines ${ }^{[23]}$.

4. Educators need to teach students how to think reflectively and not assume that this is an inherent ability ${ }^{[24]}$. Since all health professionals need highly developed reflective thinking, educators need to spend time cultivating this ability in learners. Students need to know how to learn from mistakes, how to buffer themselves against the effects of adversity, how to communicate amiably and effectively with those who have different views and how to put issues into perspective so that a vision for long term change is possible.

In 2011, an action research project was conducted involving 25 participants who were educators working in a range of health disciplines, engaged in cycles of discussion, STAR application and group reflection ${ }^{[25]}$. In addition to strong evidence for the utility of STAR, a new lesson plan was devised to accommodate the elements of STAR, a range of STAR teaching strategies were developed and published so that future educators can access them and build a growing bank of shared resources. Included in this research population were six novice nurse educators, some of whom were sessional and others full time employed, who successfully learned about transformative learning and subtly yet powerfully reoriented their teaching style.

Findings confirmed that which has been commented upon in the literature about challenges facing education in health disciplines - educators held implicit but not explicit values and views about pedagogy ${ }^{[7,8]}$; they struggled with how to engage learners in discussion whilst covering the content of their curriculum ${ }^{[9]}$; they felt they were facing a diverse student body, yet one that on the whole lacked professional passion and know-how; and students generally took to reflective challenges in superficial ways ${ }^{[24]}$.

The study also produced several new insights amongst participants that if applied, will help to enhance educator practice, and student outcomes. It is more important for educators to identify and explore threshold concepts - that is critical concepts that are defining for the advancement of nursing practice - than to overload students with more and more content. Health conditions can have an enormous impact on peoples' lives, particularly those people who come from marginalised positions or vulnerable populations and these need to be taught to students in ways that students will always remember, thus there is need for further development and sharing of effective teaching strategies. If educators want students to reflect on practice so that they can self-correct, and transfer learning from one context to another, then educators need to develop expertise in asking questions in a deliberately crafted way and not simply expect students to know how to reflect and to respond in profound ways. Students' responses will necessarily be tentative, and thus the educator's role, as one participant stated would be to use the expertise of their profession to guide a dialogue to meaning. The student's confusion is recognized, accepted, tolerated and then addressed. The students will find their own meaning from the experience through self-reflection and not just mimic what they believe is expected of them without thought.

Throughout the study, several lesson plans were developed, which now act as concrete examples that others can access to utilise or extend (see Table 1). 
Table 1: An example lesson plan ${ }^{[26-28]}$

\begin{tabular}{|c|c|c|c|c|}
\hline \multicolumn{5}{|c|}{ LESSON PLAN } \\
\hline \multicolumn{3}{|c|}{ Semester 12011} & \multicolumn{2}{|l|}{ Course: NURXXX } \\
\hline \multicolumn{3}{|c|}{ J C } & \multicolumn{2}{|l|}{ Topic: Understanding errors } \\
\hline \multicolumn{5}{|c|}{$\begin{array}{l}\text { Need for transformative learning } \\
\text { It is common for people to believe that errors can be prevented through individual competence and supervision. Yet, patient safety } \\
\text { audits reveal that sometimes complex environments and system failures may be at fault. Health services involve complexity, and } \\
\text { unpredictable events, leading to errors. No one person is at fault. In addition to individual competence, long term solutions require } \\
\text { dialogue, respect and support. }\end{array}$} \\
\hline \multicolumn{5}{|c|}{$\begin{array}{l}\text { Learning Outcomes } \\
\text { - Students will be aware that medication errors are frequent } \\
\text { - Students will be more aware of the reasons for medication errors in complex environments } \\
\text { - Students will implement supportive practices with self and others so that errors are revealed rather than hidden, and help to } \\
\text { cultivate a no blame culture. }\end{array}$} \\
\hline \multicolumn{2}{|c|}{ STAR prompt } & \multicolumn{2}{|c|}{ Duration, Description of activity, with rationales } & Resources \\
\hline \multicolumn{2}{|c|}{$\begin{array}{l}\text { Sensitizing } \\
\text { Describe the sensitizing activity }\end{array}$} & \multicolumn{2}{|c|}{$\begin{array}{l}\text { Viewing of a video “Just an ordinary day..” in which a patient is } \\
\text { inadvertently given the incorrect medication by the incorrect route with } \\
\text { fatal consequences. }\end{array}$} & $\begin{array}{l}\text { W.H.O. } \\
\text { Vincristine } \\
\text { video }\end{array}$ \\
\hline \multicolumn{2}{|c|}{$\begin{array}{l}\text { Taking action } \\
\text { Describe what knowledge, attributes } \\
\text { or skills students will have practice } \\
\text { putting into action }\end{array}$} & \multicolumn{2}{|c|}{$\begin{array}{l}\text { - Students apply the root cause, "fishbone” or "Ishikawa” diagram to } \\
\text { the video to identify the events that led to the incorrect medication } \\
\text { administration. } \\
\text { - Students complete a worksheet and the fishbone analysis to identify } \\
\text { patient factors, individual factors, communication issues, task } \\
\text { factors, standard operating procedures, education and training } \\
\text { factors, team factors, working conditions, equipment and resources } \\
\text { and organisational factors which contributed to the outcome for this } \\
\text { patient. } \\
\text { This will be completed by students working in groups and being able } \\
\text { to discuss their ideas on the scenario that occurred }\end{array}$} & Worksheet \\
\hline $\begin{array}{c}\text { Reflect } \\
\bullet \\
\text { - }\end{array}$ & $\begin{array}{l}\text { ive learning prompts } \\
\text { Questions that prompt } \\
\text { recollections of what } \\
\text { happened and the impact } \\
\text { What was happening in the } \\
\text { margins? What tacit } \\
\text { knowledge is revealed? } \\
\text { What silences can we learn } \\
\text { from? } \\
\text { How does this issue relate } \\
\text { to wider social issue? What } \\
\text { could be changed for the } \\
\text { future? }\end{array}$ & 2. & $\begin{array}{l}\text { After viewing the video identify the factors you can think of } \\
\text { which contributed this medication error. } \\
\text { As a newly graduated RN you will be faced with situations in } \\
\text { which you need to be the patient advocate. } \\
\text { Identify } 2 \text { strengths you have and a weakness which may affect } \\
\text { your ability to act in situations in the workforce. How can you } \\
\text { develop the skills you need? } \\
\text { There are many situations in nursing where you will want to } \\
\text { blame an individual for an incident. Think of a situation where } \\
\text { you can apply the fishbone analysis to change the way you view } \\
\text { things. }\end{array}$ & \\
\hline
\end{tabular}

Along with learning objects, these lesson plans provide the beginnings of a bank of resources which will stimulate the dialogue and creative activity that is envisioned for the Community of Practice previously outlined. 


\section{Conclusion and future challenges}

The shortage of nurse educators is exacerbated by role overload, insufficient support and difficulty accessing educational expertise when sessional educators are performing dual roles as clinician and teacher. The two approaches discussed in the paper are an attempt to contribute to solutions for the educator shortage. If educators can be offered membership to a community of peers who are all interested in developing and sharing creative approaches to teaching, they may develop confidence and expertise to manage the role. They may also feel more supported which will improve satisfaction, self-efficacy, and retention. If novice and sessional educators have access to a memorable and simple education framework pedagogical expertise may develop.

Ultimately these improvements benefit students, individual educators, and the profession of nursing education. For the proposed community of practice and the STAR framework to have enduring impact, they need to be funded, championed, disseminated, and further researched.

\section{Acknowledgements}

There are several people I wish to acknowledge for their input into one or both of the solutions identified in this paper. They include: Sandra Campbell, Janice Cope, Teresa Downer, Ann Framp, Tara Gamble, Julie Hanson, Christian Jones, Tracy Levett-Jones, Teressa Schmidt, and Kerry Reid-Searl. I wish to acknowledge the School of Health and Sport Sciences for providing funding to support the study reported in this paper and again to Janice Cope who provided the described lesson plan. I also want to thank the many academic colleagues within the University who participated in the study and willingly discussed their craft and were open to ideas for improvement.

\section{Source(s) of support}

School of Health and Sport Sciences, University of the Sunshine Coast

\section{References}

[1] Benner P, Sutphen M, Leonard V, Day L. Educating Nurses: A Call for Radical Transformation. San Francisco, Jossey. 2009.

[2] Potempa, Redman Landstrom. Human resources in nurse education: a worldwide crisis. Collegian. 2009; 16: 19-23. http://dx.doi.org/10.1016/j.colegn.2008.12.003

[3] Joynt K, Kimball B. Blowing Open the Bottleneck: Designing New Approaches to Increase Nurse Education Capacity. A White Paper prepared for the Robert Wood Johnson Foundation, the Center to Champion Nursing in America, and the U.S. Department of Labor, Employment and Training Administration [Internet]. Accessed 20th December 2010, 2008. Available from: http://www.rwjf.org/files/research/3335.32415.pdf

[4] McAllister M, Mosel Williams L, Gamble T, Malko-Nyhan K, Jones C. Steps towards empowerment: an examination of the needs of Australian nurse educators working in training colleges, health services and universities. Cont Nurs. 2011; 38: 6-17. PMid:21854233 http://dx.doi.org/10.5172/conu.2011.38.1-2.6

[5] Aiken L, Cheung H. Nurse Workforce Challenges in the United States. OECD Health Working Papers, No. 35. 2008, Paris: OECD.

[6] Bassell K. Social media and the implications for nursing faculty mentoring: A review of the literature. Teaching and Learning in Nursing. 2010; 5: 143-148. http://dx.doi.org/10.1016/j.teln.2010.07.007

[7] Diekelmann N. "Too much content...", epistemologies' grasp and nursing education. Journal of Nursing Education. 2002, 41: 469-470. PMid:12437050

[8] Sayers J, Di Giacomo M. The nurse educator role in Australian hospitals: implications for health policy, Collegian. 2010 ; 17 (2): 77-84. http://dx.doi.org/10.1016/j.colegn.2010.04.005

[9] Ironside P. "Covering content" and teaching thinking: Deconstructing the additive curriculum. Journal of Nursing Education. 2004; 43(1): 5-12. PMid:14748529

[10] Tagliareni M, Sherman S. When ambiguity replaces certainty: New faculty roles in community settings. In M. E. Tagliareni \& B.B. Marckx (Eds.). Teaching in the community: Preparing nurses for the 21st century (pp. 20-34). 1999, Sudbury, MA: Jones \& Bartlett Publishers/ NLN Press. 
[11] Dirkx J, Mezirow J, Cranton P. Musings and reflections on the meaning, context, and process of transformative learning: A dialogue between John M. Dirkx and Jack Mezirow. Journal of Transformative Learning. 2006; 4(2): 123-139.

[12] Windsor C, Douglas C, Harvey T. Nursing and Competencies: A Natural Fit. The Politics of Skill/Competency Formation in Nursing. Nursing Inquiry. 2011; 18(3). http://dx.doi.org/10.1111/j.1440-1800.2011.00549.x

[13] Sinclair, P., Levett-Jones, T. The evolution of the nephrology educators' network. Jnl of Renal Care. 2011; 37: 40-46. PMid:21288316 http://dx.doi.org/10.1111/j.1755-6686.2011.00208.x

[14] Madsen W, McAllister M, Godden J, Greenhill J, Reed R. Nursing’s orphans: how the system of nursing education in Australia is undermining professional identity. Contemp Nurse. 2009; 32: 9-18. PMid:19697974

[15] Valiga TM. Why we need evidence-based teaching practices in Levin, R.F. \& Feldman, H.R. eds. 2006. Teaching Evidence-Based Practice in Nursing: A Guide for Academic and Clinical Settings. New York, Springer. 2006; 261-274.

[16] Palmer P. The courage to teach. 1998. San Francisco: Jossey-Bass.

[17] Wenger D. Communities of Practice: Learning, Meaning, and Identity. 1998, Cambridge, Cambridge University Press.

[18] McDonald J, Star C. Designing the future of learning through a community of practice of teachers of first year courses at an Australian university. In The First International LAMS Conference: Designing the Future of Learning. 2006; 6-8.

[19] Mezirow J. Learning as Transformation. 2000. San Francisco: Jossey-Bass.

[20] McAllister M. STAR: A transformative learning framework for nursing education. Journal of Transformative Education. (In press).

[21] Hart T. Opening the contemplative mind in the classroom. Journal of Transformative Education. 2004; 2(1): 28-46. http://dx.doi.org/10.1177/1541344603259311

[22] Meyer J, Land R. Overcoming Barriers to Student Understanding: threshold concepts and troublesome knowledge. 2006. New York: Routledge.

[23] Grundy, S. The concept of praxis, in S. Grundy (Ed). Curriculum: Product or praxis? London: Falmer Press. 1987; $104-114$.

[24] Freshwater D. Therapeutic nursing: Improving patient care through self-awareness and reflection. 2002. London: Sage.

[25] McAllister M, Oprescu F, Downer T, Lyons M, Pelly F, Barr N. Evaluating STAR - a transformative learning framework: Interdisciplinary action research in health training. Action Research Journal (under review).

[26] Ishikawa, K. (Translator: J. H. Loftus). Introduction to Quality Control.1990; 448p.

[27] World Health Organization. Patient Safety Workshop: Learning From Error. National Patient Safety Report, NHS, UK. 2008.

[28] DVD: Just an Ordinary Day [Internet]. Available from: http://who.int/patienytsafety/education/vincristine_download 